\title{
Mathematical Method for Predicting Nickel Deposit Based on Data from Drilling Points
}

\author{
Edi Cahyono ${ }^{1}$, Sapto Rahardjo $^{2}$, Asrul Sani ${ }^{3}$
}

\begin{abstract}
In this article we discuss several methods for predicting nickel ore content inside the soil under a given area/region. The prediction is the main objective of the exploration activity which is very important for conducting the exploitation activity from economic point of view. The prediction methods are based on the data obtained from the drilling activity at several 'points'. The data yields information on the nickel density at those points. Nickel density over the region is approximated (with an approximate function) by applying interpolation and/or extrapolation based on the data from those points. The nickel content is predicted by applying integral of the approximate function over the given region.
\end{abstract}

Keywords: Nickel, exploration, drilling, prediction methods, interpolation - extrapolation.

\section{Introduction}

This article was motivated by the site visit of Mathematics Department, Universitas Haluoleo, to PT Aneka Tambang (Persero) Tbk in Pomalaa, Kolaka, Southeast Sulawesi. We then call the mining company as PT Antam. The main purpose of the visits, which are conducted to some industries in regular basis every year, is to improve the quality as well as the quantity of applied mathematics researches in industrial fields. This activity also promotes the applications of mathematics in a practical way in improving industrial processes including efficiency, effectiveness and accuracy of a process. This article is one of the examples of mathematics application in the nickel mining industry (Ni). Another motivation of this study is the fact that only a few literatures have discussed the nickel ore mining in Indonesia, two references that authors are able to trace include by Guiry and Dalvi [5] and by van Leeuwen [8].

As in other mining processes, nickel ore mining activities also involve the exploration, exploitation, and processing of mining products in factories. Exploration activities include geological mapping in the form of structural materials, bedding planes, fracture and fault whereas drilling is to determine the mineral deposit and the ore depth.

${ }^{1,3}$ Faculty of Mathematics and Natural Sciences, Department of Mathematics, Universitas Haluoleo. Л. HEA Mokodampit, Kendari 93232. Email: edi_cahyono@innov-center.org, saniasrul2001@ yahoo.com

2 Faculty of Mathematics and Natural Sciences, Department of Chemistry, Universitas Haluoleo. Л. HEA Mokodampit, Kendari 93232. Email: saprjo@yahoo.com

Received 19th January 2011; revised1 15th August 2011; accepted for publication 7th September 2011.
From the exploration activities, one can also determine what types as well as the form of minerals reserved and the amount of deposit underneath the area. In some cases, the nickel deposit relates to the distribution of gold in the area, Sibbick and Fletcher [16].

Exploitation is essentially taking out (mining) mineral ore from the earth. The exploitation activity is carried out only if the results of study, including risk analysis, show that it is, in particular, economically feasible, for instance, see Guj [6]. The exploittation activities (illustrated in Figure 1) include: Clearing out forest. Stripping of top soil and overburden, top left. Top soil is a layer of soil containing nutrients. Overburden is the soil just under the top soil and does not contain nutrients. In the mining process, the top soil and overburden are collected in one place and will be restored again after the mining is completed. This is intended to minimize the impact of environmental destruction due to the mining. Excavating of minerals, middle. Minerals are then taken out/mined/ removed from the site in situ by using excavators. Transportation of ore materials to the landfill (stockyard), bottom.

The nickel ore processing at the plant includes several stages: (1) Nickel ore from mining sites is collected in the stockyard. In semi continuous, nickel ore undergoes a drying process through a sieve (SOM). This process is using the rotary dryer (Rotary Dryer) at a temperature of $600{ }^{\circ} \mathrm{C}$ to reduce the nickel ore moisture from $30 \%$ to $21 \%$. (2) The dried nickel ore is stored in the ore bins with a capacity of 120 tons. Besides those for nickel ore, there are other bins which are used to store raw materials such as anthracite / coal and limestone. (3) All together with other supporting materials, nickel ore is continuously put into the rotary kiln (Rotary Kiln). The material 


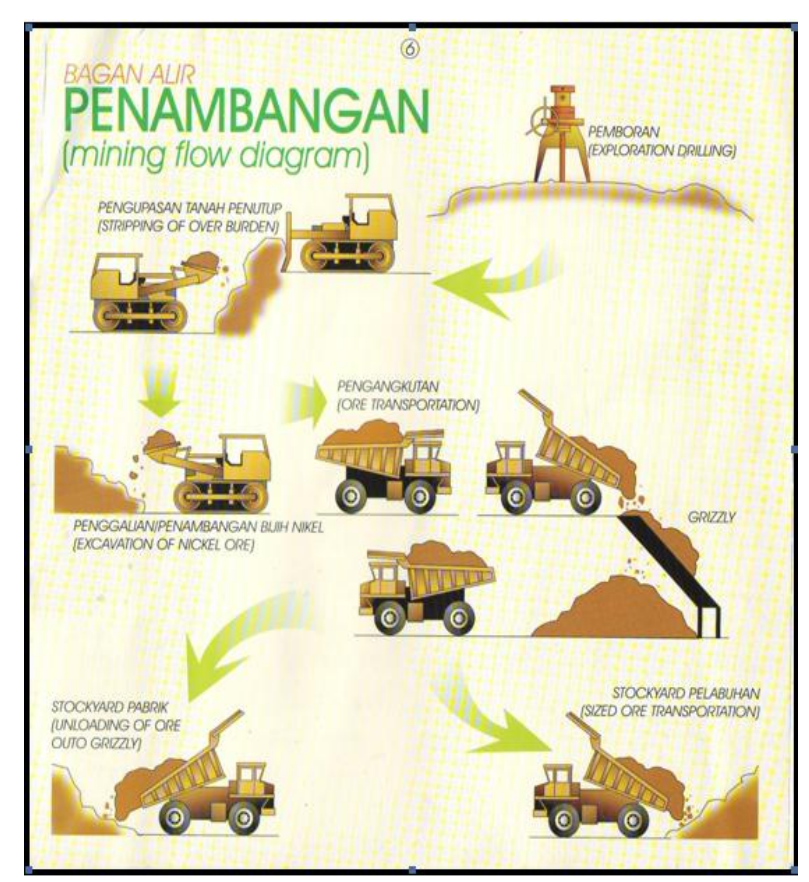

Figure 1. Scheme of nickel exploitation/mining activities. Source from a brochure PT Aneka Tambang (Persero) Tbk.

coming out from the rotary kiln is called Calcine ore. (4) Then, Calcine ore is inserted/ fed into the furnaces (smelter/furnace). Ferronickel is produced in the furnace. Ferronickel production process requires a very large electrical energy (each furnace needs electrical energy at about $17 \mathrm{MW}$ per hour). (5) Intermittently, ferronickel liquid is removed from the furnace. Then, it is purified on Rafinery by flowing oxygen $\left(\mathrm{O}_{2}\right)$ into the liquid metal. The liquid metal is then ready to produce. The type of ferronickel produced can be either High or Low Carbon. In terms of the shape, the ferronickel produced can be in the shape of bar (ingot) or granules (shot).

Before the stage of exploitation is preceded, the exploration should guarantee the feasibility at least from an economic perspective that the mining is profitable. This, of course, requires the knowledge of nickel deposit in the areas where the mining process will be carried out. Unfortunately, this amount cannot be measured directly but calculated based on the existing data, including density of nickel drilling results at several points.

The units of all variables in this study will use the International System Units (SI). The rest of this article is organized as follows. Section of methods describes the mathematical model of nickel deposit in a particular mining area/region (in mathematics term it is called a "bounded and finite domain"). The model itself is in the form of a double integral of the nickel 'density' function which is defined at all points on the mining domain. However, the main issue is the fact that the nickel density function is not known. Therefore, this function will be approximated based on the data of the nickel density obtained from the drilling at several sites. The developed method of estimation is presented in this section. Section results and discussion deals with numerical simulation and the error analysis of the proposed approach. Finally, we end with the discussion of the conclusions and the directions of future research.

\section{Methods}

\section{Mathematical Model}

There are many steps required in the exploration in order to obtain information about the amount of nickel reserves underneath the earth. One of those is the use of soil samples in the geochemical exploration techniques as carried out, for example, by Worthington et al. [18], Miller et al. [13], Li et al. [9], Brand [2], and Kebede [7], or by combining soil samples and some data from plants in the biogeochemical techniques as practiced by McInnes et al. [12] in Papua New Guinea.

The nickel identified in plants, in one side, indicates only the nickel reserved in the soil where they grow. However, the nickel found in the soil samples suggests its density in the soil. If the sample is obtained from a drilling point (as commonly practiced by mining companies), then it will represent the density of nickel deposit in the drilling point. In this study, we will develop a mathematical model based on the data of nickel density obtained from the results of drilling at several points.

It is reasonable to assume that the mining area is very small compared to the whole surface of the earth. Therefore, this area can be considered as a flat field. Suppose $\Omega \in \mathbb{R}^{2}$ represents a concerned mining area, where $\mathbb{R}$ is a set of real numbers and $\mathbb{R}^{2}$ is a Cartesian product of two sets of real numbers. More about the mathematical concept of a closed and finite set as well as its corollaries, one can read the theory of calculus or the introductory of real analysis, see for example, Bartle and Sherbert [1]. The unit for the area is meter square $\left(\mathrm{m}^{2}\right)$. Practically, it is possible to determine the boundaries of $\Omega$ based on the fact that it is not allowed mining outside the region, for example, because it is not profitable or due to the conservation or settlement area.

Suppose $f$ is a nonnegative function defined on the real numbers, and $f(x, y)$ represents the nickel density at the point $(x, y) \in \Omega$. The function $f$ has unit $\mathrm{kg} \cdot \mathrm{m}^{-2}$. Thus, the nickel deposit in the area $\Omega$ is given by 
$m=\iint f(x, y) d x d y$

Note that the mass $m$ in (1) has a unit $k g$. The value of integral in (1) is very important as it determines whether or not the exploitation is feasible. Although the integral in (1) looks simple, however, in practice it is not straightforward to solve. Before presenting why and how the problem can be handled, we first give the following remark.

\section{Remark 1}

It is assumed that the depth of drilling is ignored. Thus, we only consider the surface area. The nickel density at a certain point means as the density which can be 'taken' by drilling beneath that point up to a possible depth. Therefore, the international system (SI) unit for the density is given as $\mathrm{kg} . \mathrm{m}^{-2}$.

The reason why the calculation of integral (1) is not straightforward can be explained as follows. In general, the value of the function $f$ is not known as we do not have any knowledge what is the nickel density underneath the earth at any point on the surface. Therefore, the nickel deposit would be predicted on the basis of drilling data at several sites. The function $f$ will be approximated from several available data. Suppose there are $N$ drilling locations/points, say $(x, y) \in \Omega$ for $1<i<N$ and the nickel density at the $i$ th point is denoted as $\rho_{i}$ Then, we have

$\rho_{i}=f\left(x_{i}, y_{i}\right)$ for $1<i<N$

This is illustrated in Figure 2.

The main concern in this study is, "how to predict (1) based on data (2)?" The following remark is based on the field study.

\section{Remark 2}

On PT Antam, Pomalaa Mining, Kolaka, Southeast Sulawesi, the distance between two adjacent drilling points is $25 \mathrm{~m}$. This drilling technique is considered as a detail exploration.

\section{Methods for Prediction}

There are many methods to predict (1) based on (2), including statistical models such as the Bayesian weighted models and logistic regression by Porwal et al. [15]. Mamuse et al. [10] has applied regression models to predict the density of nickel deposit. In this section, we will discuss some proposed techniques and their analysis based on the mathematical perspective. Unlike the models proposed by Porwal et al. [15] and Mamuse et al [10] which are based on statistical model, the method we will develop in this article is a deterministic model.

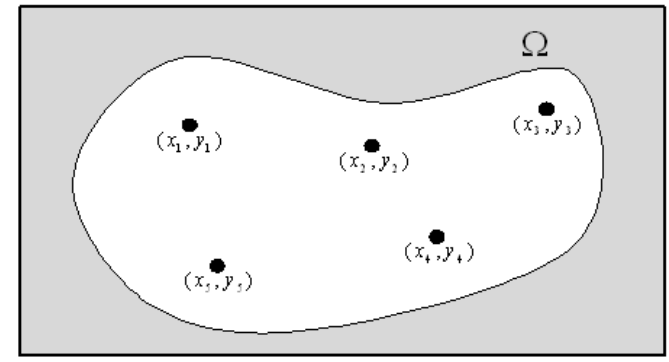

Figure 2. The abstraction of nickel mining regions (the enclosed curve) and the locations of exploitation drilling (points)

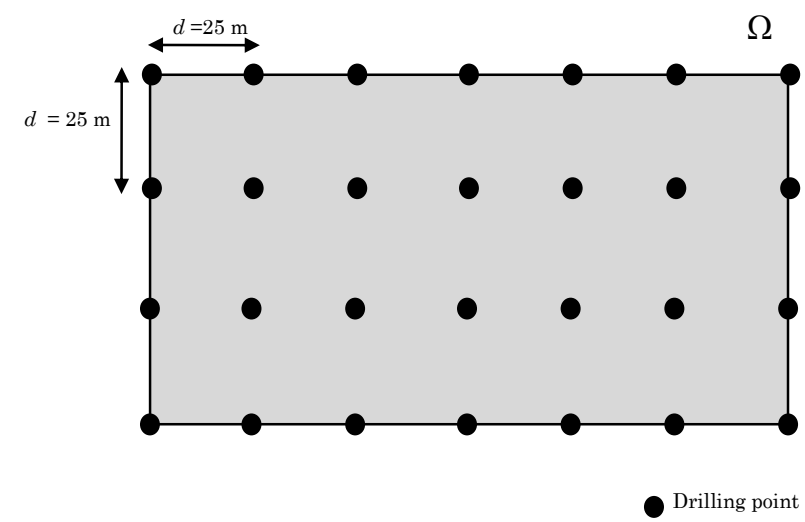

Figure 3. Illustration of drilling points on rectangle-shaped mining area.

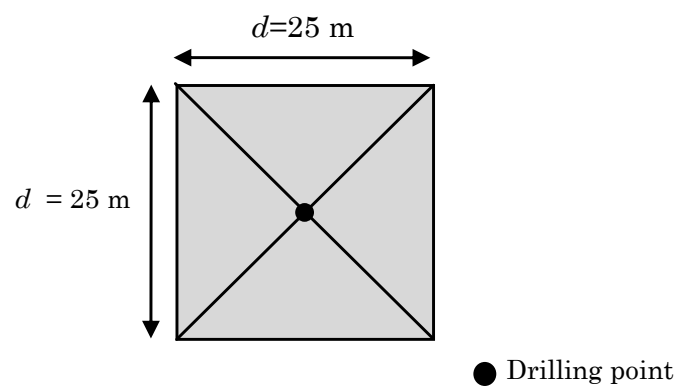

Figure 4. The drilling point as the diagonal intersection of a square with sides $25 \mathrm{~m}$.

\section{The Method used at PT Aneka Tambang (Persero) Tbk}

In this section, we briefly discuss the method used at PT Antam to predict the nickel deposit. The distance of exploration drilling sites used in PT Antam, see Remark 1, is 25 m, as illustrated in Figure 3.

Table 1 shows an example of some collected data from PT Antam. And, the prediction method assumes that the drilling point is on the diagonal intersection of a square with side $25 \mathrm{~m}$, as illustrated in Figure 4.

Note that we do not show the complete data as they might have some important information for the company and the discussion is limited only on the basic approach. 
Table 1. Some collected data from several drilling sites

\begin{tabular}{|c|c|c|c|c|c|c|c|c|c|c|c|c|c|c|c|c|}
\hline SampNo & EASCO & NORCO & ELEV & Level & & $\mathrm{Ni}$ & Co & $\mathrm{Fe}$ & $\mathrm{SiO} 2$ & $\mathrm{CaO}$ & MGO & $\mathrm{S} / \mathrm{M}$ & $\mathrm{Fe} / \mathrm{Ni}$ & $\mathrm{BC}$ & $\mathrm{LP}$ & TAMB \\
\hline 60 & -5675 & -5909.6 & 133.9 & 17 & 16 & 1.26 & 12 & 7.70 & .38 & 1.17 & 1.80 & 2.49 & 8 & ? & & U \\
\hline 6 & -5675 & & 133.9 & 1 & 17 & 1.35 & 3 & 22 & 31 & 1.27 & & 1.29 & & & & \\
\hline 60 & 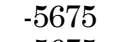 & & 1330 & 19 & 18 & 1. & 4 & & & 0.70 & & 1.31 & & 0 & 62 & $(0$ \\
\hline 60 & -5675 & 5911.4 & 133.9 & 20 & 19 & 0.92 & 0.04 & 15.92 & 51.63 & 0.57 & 16.46 & 2.53 & 17.30 & 0.41 & 625 & 0 \\
\hline
\end{tabular}

It is assumed that the nickel density is uniformly distributed in the square. Suppose that there are $N$ drilling points, and the density at the $i$ th drilling point is $\rho_{i}$ for $1 \leq i \leq N$. Thus, the nickel density in the square, at the $i$ th drilling point, is $\left(\rho_{i} . \Delta A\right)$, with. $\Delta A=25 \mathrm{~m} \times 25 \mathrm{~m}$. So, the total nickel deposit in the exploration area is given by

$m=\sum_{i=1}^{N}\left(\rho_{i} \cdot \Delta A\right)=\Delta A \sum_{i=1}^{N} \rho_{i}$

Note that the total area considered in this case is just $N . \Delta A$.

\section{Method of Averaging}

The simplest way to calculate the integral in (1) is by applying the average method. This method assumes that the nickel density on $\Omega$ is equal to the average of the nickel densities for all drilling points as given by

$\bar{\rho}=\frac{\sum_{i=1}^{N} \rho_{i}}{N}$

Therefore, the value of integral in (1) is approximated by

$m=\iint_{\Omega} \bar{\rho} d x d y=\bar{\rho} \iint_{\Omega} d x d y=\bar{\rho} . \Omega$

Strictly speaking, notation (5) states that the nickel deposit is $\bar{\rho}$ times of the total area $\Omega$.

The relation between the average method (5) and the method used by PT Antam is as follows. By using (4), Equation (3) can be written as

$m=\Delta A \sum_{i=1}^{N} \rho_{i}=(N . \Delta A) \frac{\sum_{i=1}^{N} \rho_{i}}{N}=(N . \Delta A) \bar{\rho}$

As we also call the area as $\Omega$, i.e., $N . \Delta A=\Omega$, equation (6) is equivalent to (5). Therefore, the method used by PT Antam is basically just the simple average method.

Let us consider $\Omega$ as a closed and bounded set, and $f(x, y)$ is a continuous function defined on $\Omega$. With the mean value theorem of multivariable integral, it guarantees that there exists a point $\left(x_{0}, y_{0}\right) \in \Omega$ such that

$\iint_{\Omega} f(x, y) d x d y=f\left(x_{0}, y_{0}\right) \iint_{\Omega} d x d y=f\left(x_{0}, y_{0}\right) \Omega$
For more discussion of the multivariable integral and the mean value theorem, one can refer to some textbooks, see for example, the multiple variable functions (Felming [4]), advanced calculus (Taylor and Mann [17]), and vector calculus (Marsden and Tromba [11] or Corwin and Szczarba [3]).

Therefore, the method would accurately predict the nickel content if the average of all nickel density for all drilling sites is equal to $\bar{\rho}=f\left(x_{0}, y_{0}\right)$. In theory, it is enough to drill at that point $\left(x_{0}, y_{0}\right)$ and the prediction will be accurate. Although it is guaranteed the existence of this point on $\Omega$, to find such point itself is, however, a different issue. In practice, it is almost impossible to determine that point.

\section{Piecewise Linear Method}

Piecewise linear method is a more advanced method than the average one. This method can be explained as follows. Suppose we look a rectangle-shaped area $\Omega$ with the length and the width $m$ and $n$, respectively, and the distance between two adjacent drilling points is $d=25 \mathrm{~m}$, see Figure 4 . So, there are $m \times n$ drilling points in the area $\Omega$, say $Z_{i, j}$, for $i=1,2, \ldots, m$ and $j=1,2, \ldots n$.

To approximate the density function using a piecewise linear method, we do as follows. We consider a isosceles right triangle (as partition of the region) with the vertices, $\left(x_{1}, y_{1}\right),\left(x_{1}, y_{2}\right)$ and $\left(x_{2}, y_{1}\right)$. The density of nickel in these vertices are known based on the data of drilling, say $Z_{1,1}, Z_{1,2}$ and $Z_{2,1}$, respectively. Then, the nickel density at the point $(x, y)$ in the triangle-shaped domain is approximated linearly based on the values $Z_{1,1}, Z_{1,2}$ and $Z_{2,1}$. Thus, the nickel density in the domain $\left(x_{1}, y_{1}\right),\left(x_{1}, y_{2}\right)$ and $\left(x_{2}, y_{1}\right)$ is the volume of a trapezoid with a triangle base and a plane, passing through the points $\left(x_{1}, y_{1}, z_{1,1}\right),\left(x_{1}, y_{2}, z_{1,2}\right)$ and $\left(x_{2}, y_{1}, Z_{2,1}\right)$, on top part, as illustrated in Figure 4 . The volume of the trapezoid is given by

$V_{1,1,1}=\frac{\left(Z_{1,1}, Z_{1,2}, Z_{2,1}\right) d^{2}}{6}$

One can see that Equation (8) is just the product of the area of the right isosceles triangle $\frac{1}{2} d^{2}$ and the average of density from three drilling points $\frac{1}{3}\left(Z_{1,1}+Z_{1,2}+Z_{2,1}\right)$. 


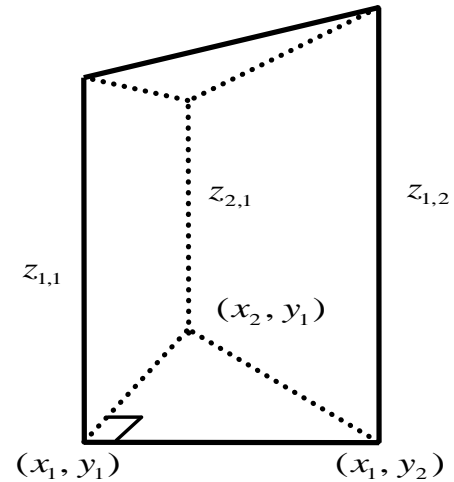

Figure 5. Nickel content under a triangular surface area.

So, there are $2(m-1)(n-1)$ right isosceles triangles with the isosceles length $d$ on the rectangle area $\Omega$;

$A_{i, j}$ with vertices $\left(x_{i}, y_{j}\right),\left(x_{i}, y_{j+1}\right),\left(x_{i+1}, y_{j}\right)$, corresponding to drilling data on these vertices $Z_{i, j}, Z_{i, j+1}, Z_{i+1, j}$, respectively, for $i=1,2, \ldots, m-1$ and $j=1,2, \ldots, n-1$.

$A_{2 i, j}$ with vertices $\left(x_{i+1}, y_{j+1}\right),\left(x_{i}, y_{j+1}\right),\left(x_{i+1}, y_{j}\right)$, corresponding to drilling data on these vertices $Z_{i+1, j+1}, Z_{i, j+1}, Z_{i+1, j}$, for $i=1,2, \ldots, m-1$ and $j=1,2, \ldots, n-1$.

This is illustrated in Figure 6. In general, nickel deposit in the area $A_{i, j}$ is given by

$V_{1, i, j}=\frac{\left(z_{i, j}, Z_{i, j+1}, Z_{i+1, j}\right) d^{2}}{6}$

and the nickel deposit in $A_{2 i, j}$ is given by

$V_{2, i, j}=\frac{\left(Z_{i+1, j+1}, Z_{i, j+1}, Z_{i+1, j}\right) d^{2}}{6}$

Therefore, the total nickel deposit reserved in the rectangle area $\Omega$ is

$V_{i, j}=$

$\sum_{i=1}^{m-1} \sum_{j=1}^{n-1}\left(V_{1, i, j}+V_{2, i, j}\right)=\frac{d^{2}}{6} \sum_{i=1}^{m-1} \sum_{j=1}^{n-1}\left(Z_{i, j}+\right.$

$\left.2 Z_{i, j+1}+2 Z_{i+1, j}+Z_{i+1, j+1}\right)$

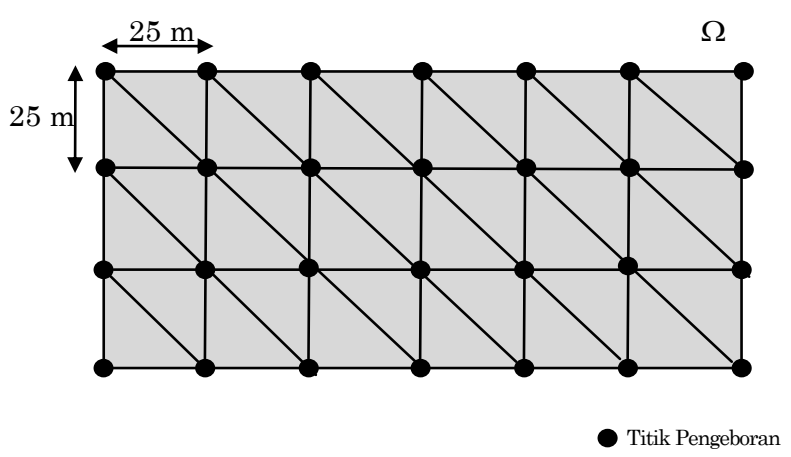

Figure 6. The partition of $\Omega$ into triangular areas to approximate the nickel deposit by using piecewise linear approach.
Table 2. Simulation data representing nickel content from several drilling sites.

\begin{tabular}{|c|c|c|c|c|}
\hline \multirow{3}{*}{$\begin{array}{c}\text { No } \\
1\end{array}$} & \multicolumn{2}{|c|}{ Drilling point } & \multirow{2}{*}{\multicolumn{2}{|c|}{$\frac{\text { Nickel content }}{\mathrm{Kg} / \mathrm{m}^{2}}$}} \\
\hline & $\mathrm{x}$ & $\mathrm{y}$ & & \\
\hline & 0 & 0 & $\mathrm{z}(1,1)$ & 1.14 \\
\hline 2 & 0 & 25 & $\mathrm{z}(1,2)$ & 1.37 \\
\hline 3 & 0 & 50 & $\mathrm{z}(1,3)$ & 1.50 \\
\hline 4 & 0 & 75 & $\mathrm{z}(1,4)$ & 1.54 \\
\hline 5 & 0 & 100 & $\mathrm{z}(1,5)$ & 1.29 \\
\hline 6 & 0 & 125 & $\mathrm{z}(1,6)$ & 1.48 \\
\hline 7 & 0 & 150 & $\mathrm{z}(1,7)$ & 1.48 \\
\hline 8 & 0 & 175 & $\mathrm{z}(1,8)$ & 1.38 \\
\hline 9 & 0 & 200 & $\mathrm{z}(1,9)$ & 0.79 \\
\hline 10 & 0 & 225 & $\mathrm{z}(1,10)$ & 0.85 \\
\hline 11 & 25 & 0 & $\mathrm{z}(2,1)$ & 0.83 \\
\hline 12 & 25 & 25 & $\mathrm{z}(2,2)$ & 1.31 \\
\hline 13 & 25 & 50 & $\mathrm{z}(2,3)$ & 1.03 \\
\hline 14 & 25 & 75 & $\mathrm{z}(2,4)$ & 1.29 \\
\hline 15 & 25 & 100 & $\mathrm{z}(2,5)$ & 1.35 \\
\hline 16 & 25 & 125 & $\mathrm{z}(2,6)$ & 1.19 \\
\hline 17 & 25 & 150 & $\mathrm{z}(2,7)$ & 1.26 \\
\hline 18 & 25 & 175 & $\mathrm{z}(2,8)$ & 1.35 \\
\hline 19 & 25 & 200 & $\mathrm{z}(2,9)$ & 1.25 \\
\hline 20 & 25 & 225 & $\mathrm{z}(2,10)$ & 0.92 \\
\hline 21 & 50 & 0 & $\mathrm{z}(3,1)$ & 1.16 \\
\hline 22 & 50 & 25 & $\mathrm{z}(3,2)$ & 1.15 \\
\hline 23 & 50 & 50 & $\mathrm{z}(3,3)$ & 1.12 \\
\hline 24 & 50 & 75 & $\mathrm{z}(3,4)$ & 1.18 \\
\hline 25 & 50 & 100 & $\mathrm{z}(3,5)$ & 1.18 \\
\hline 26 & 50 & 125 & $\mathrm{z}(3,6)$ & 1.27 \\
\hline 27 & 50 & 150 & $\mathrm{z}(3,7)$ & 0.93 \\
\hline 28 & 50 & 175 & $\mathrm{z}(3,8)$ & 0.83 \\
\hline 29 & 50 & 200 & $\mathrm{z}(3,9)$ & 0.99 \\
\hline 30 & 50 & 225 & $\mathrm{z}(3,10)$ & 1.09 \\
\hline 31 & 75 & 0 & $\mathrm{z}(4,1)$ & 1.25 \\
\hline 32 & 75 & 25 & $\mathrm{z}(4,2)$ & 0.92 \\
\hline 33 & 75 & 50 & $\mathrm{z}(4,3)$ & 1.06 \\
\hline 34 & 75 & 75 & $\mathrm{z}(4,4)$ & 0.95 \\
\hline 35 & 75 & 100 & $\mathrm{z}(4,5)$ & 0.74 \\
\hline 36 & 75 & 125 & $\mathrm{z}(4,6)$ & 0.73 \\
\hline 37 & 75 & 150 & $\mathrm{z}(4,7)$ & 1.54 \\
\hline 38 & 75 & 175 & $\mathrm{z}(4,8)$ & 1.18 \\
\hline 39 & 75 & 200 & $\mathrm{z}(4,9)$ & 1.24 \\
\hline 40 & 75 & 225 & $\mathrm{z}(4,10)$ & 1.03 \\
\hline 41 & 100 & 0 & $\mathrm{z}(5,1)$ & 0.95 \\
\hline 42 & 100 & 25 & $\mathrm{z}(5,2)$ & 1.23 \\
\hline 43 & 100 & 50 & $\mathrm{z}(5,3)$ & 1.12 \\
\hline 44 & 100 & 75 & $\mathrm{z}(5,4)$ & 0.75 \\
\hline 45 & 100 & 100 & $\mathrm{z}(5,5)$ & 0.62 \\
\hline 46 & 100 & 125 & $\mathrm{z}(5,6)$ & 1.04 \\
\hline 47 & 100 & 150 & $\mathrm{z}(5,7)$ & 1.06 \\
\hline 48 & 100 & 175 & $\mathrm{z}(5,8)$ & 1.12 \\
\hline 49 & 100 & 200 & $\mathrm{z}(5,9)$ & 0.89 \\
\hline 50 & 100 & 225 & $\mathrm{z}(5,10)$ & 1.03 \\
\hline
\end{tabular}

\section{Result and Discussion}

\section{Simulation}

Suppose we have data of nickel content at several drilling points as given in Table 2. We also write the index of the value and the point coordinates in the table. Note that the data is for simulation purpose 
only, and we do not consider real industrial data for the sake of company privacy. Here we consider an area of $22,500 \mathrm{~m}^{2}$ in the form of rectangle $225 \mathrm{~m}$ by $100 \mathrm{~m}$.

To predict the nickel content under this area, in general we may apply any methods. Applying the piecewise linear method, we exploit equation (11) to have prediction of nickel content which is

To predict the nickel content under this area, in general we may apply any methods. Applying the piecewise linear method, we exploit equation (11) to have prediction of nickel content which is

$V=25,294.79167 \mathrm{Kg}$.

Note that, the computation is very simple for the case of 50 points may be done manually by using standard calculator. The way of obtaining equation (11) is, however, more important than the computation. On the other hand, the error of this prediction is our concerned.

\section{Error Analysis}

In this part we will discuss the error analysis of the proposed method presented in the previous section. One should note that the error prediction cannot be avoided in the exploration activities. However, an exploration without any prediction can cause huge losses.

The error due to the method used by PT Aneka Tambang (Persero) Tbk is just the error of the average method. This error can be calculated as the following formula

$$
E=\left|\iint_{\Omega} f(x, y) d x d y-\bar{\rho} \iint_{\Omega} d x d y\right|
$$

Using the average multi-variable integral theorem, the magnitude of these errors is obtained as

$$
E=\left|f\left(x_{0}, y_{0}\right)-\bar{\rho}\right| \iint_{\Omega} d x d y=\left|f\left(x_{0}, y_{0}\right)-\bar{\rho}\right| \Omega
$$

with $f\left(x_{0}, y_{0}\right)$ as the density of nickel at the point $\left(x_{0}, y_{0}\right)$ on the mining area. This error will be equal to zero if the average density of sample data equal to the nickel density $f\left(x_{0}, y_{0}\right)$ at the point $\left(x_{0}, y_{0}\right)$.

Meanwhile, the error factor in the general piecewise linear method (11) is obtained as the absolute value of the difference (1) and (11), that is

$$
\begin{aligned}
& E=\mid\left(\iint_{\Omega} f(x, y) d x d y\right)-\left(\sum _ { i = 1 } ^ { m - 1 } \sum _ { j = 1 } ^ { n - 1 } \left(V_{1, i, j}+\right.\right. \\
& \left.\left.V_{2, i, j}\right)\right) \mid
\end{aligned}
$$

In this case, one can calculate the integral (1) on each triangle as the partition of $\Omega$ Thus (13) becomes

$E=$

$\mid \sum_{i=1}^{m-1} \sum_{j=1}^{n-1}\left(\iint_{A_{1, i, j}} f(x, y) d x d y+\right.$

$\left.\iint_{A_{2, i, j}} f(x, y) d x d y\right)-\left(\sum_{i=1}^{m-1} \sum_{j=1}^{n-1}\left(V_{1, i, j}+V_{2, i, j}\right)\right)$

$=\mid \sum_{i=1}^{m-1} \sum_{j=1}^{n-1}\left(\left(\iint_{A_{1, i, j}} f(x, y) d x d y-V_{1, i, j}\right)+\right.$

$\left.\left(\iint_{A_{2, i, j}} f(x, y) d x d y-V_{2, i, j}\right)\right) \mid$

$\leq \sum_{i=1}^{m-1} \sum_{j=1}^{n-1}\left(\left|\iint_{A_{1, i, j}} f(x, y) d x d y-V_{1, i, j}\right|+\right.$

$\left.\left|\iint_{A_{2, i, j}} f(x, y) d x d y-V_{2, i, j}\right|\right)$

Based on the mean value theorem of integral, there is a point on the triangle $A_{1, i, j}$ and $A_{2, i, j}$, say $\left(\tilde{x}_{1, i, j}, \tilde{y}_{1, i, j}\right)$ and $\left(\tilde{x}_{2, i, j}, \tilde{y}_{2, i, j}\right)$, respectively, that satisfies

$\iint_{A_{1, i, j}} f(x, y) d x d y=f\left(\tilde{x}_{1, i, j}, \tilde{y}_{1, i, j}\right) \frac{d^{2}}{2}$

and

$\iint_{A_{2, i, j}} f(x, y) d x d y=f\left(\tilde{x}_{2, i, j}, \tilde{y}_{2, i, j}\right) \frac{d^{2}}{2}$

For $\quad i=1,2, \ldots, m-1 \quad$ and $\quad j=1,2, \ldots, n-1$. Consequently, the inequality (14), by using (9)-(10) and (15)-(16), can be written into

$E \leq \frac{d^{2}}{2} \sum_{i=1}^{m-1} \sum_{j=1}^{n-1}\left(\begin{array}{c}\left|f\left(\tilde{x}_{1, i, j}, \tilde{y}_{1, i, j}\right)-\frac{\left(z_{i, j}+z_{i, j+1}+z_{i+1, j}\right)}{3}\right| \\ +\left|f\left(\tilde{x}_{2, i, j}, \tilde{y}_{2, i, j}\right)-\frac{\left(z_{i+1, j}+z_{i, j+1}+z_{i+1, j}\right)}{3}\right|\end{array}\right)$

as the error margin of the proposed method, i.e., the piecewise linear method.

\section{Conclusion}

We have briefly discussed the exploration and exploitation process in nickel mining. From the economic perspective, it is very important to have an accurate approximation of the nickel deposit prior to the exploitation process. The main objective of the exploration activities is to predict the nickel deposit. The prediction is based on the data at some drilling points. PT Aneka Tambang (Persero) Tbk. has applied the average double integral in predicting the nickel deposit in its mining area. In mathematical theory, if the function of nickel density is continuous and bounded at any point in a domain area, it must exist a point as the average nickel density over the area.

In this study, we have proposed an alternative mathematical method in predicting nickel deposit in a certain region by using a piecewise linear 
approach. This method assumes that at each triangle where its vertices are three adjacent drilling points the function of nickel content is linear. We have shown as well that an integral approach with the piecewise linear approach performs better than that with the average approach. Future research will focus on the implementation of this method in predicting nickel deposit in a certain region based on available field data, and it will be on the stage of industrial research.

\section{Acknowledgment}

The authors would like to thank to Mr. Aji Brata Galina from PT Aneka Tambang (Persero) Tbk, mining Pomalaa, Kolaka, Southeast Sulawesi, for his valuable suggestions and long-distance discussions, and Muharam Tahir for conducting practical training on this subject, Dr. Siana Halim and unonimous referees for their valuable suggestion.

\section{References}

1. Bartle, R. G., and Sherbert, D. R., Introduction to Real Analysis, John Wiley and Son Inc., Singapore, 1994.

2. Brand, N. W., Element Ratio in Sulphite Exploration: Vectoring Towards Ore Environment, Journal of Geochemical Exploration, 67(13), 1999, pp. $145-165$.

3. Corwin, L. J., and Szczarba, R. H., Calculus in Vector Spaces, $2^{\text {nd }}$ ed., Marcel Dekker, Inc., New York, 1995.

4. Fleming, W., Functions of Several Variables, $2^{\text {nd }}$ ed., Springer-Verlag, New York, 1977.

5. Guiry, J. D., and Dalvi, A. D., P.T. INCO's Indonesian Nickel Project: An Updating, International Journal of Mineral Processing, 19(1-4), 1987, pp. $199-214$.

6. Guj, P., Statistical Considerations of Progressive Value and Risk in Mineral Exploration, Resources Policy, 33(3), 2008, pp. 150 - 159.

7. Kebede, F., Use of Termite Mounds in Geochemical Exploration in North Ethiopia, Journal of African Earth Sciences, 40(1-2), 2004, pp. $101-103$.

8. van Leeuwen, T. M., 25 Years of Mineral Exploration and Discovery in Indonesia, Journal of Geochemical Exploration, 50(1-3), 1994, pp. 13-90.
9. Li, Y., Cheng, H., Yu, X., and Xu, W., Geochemical Exploration for Concealed NickelCopper Deposits, Journal of Geochemical Exploration, 55(1-3), 1995, pp. 309 - 320.

10. Mamuse, A., Beresford, S., Porwal, A., and Kreuzer O., Assessment of Undiscovered Nickel Sulphide Resources, Kalgoorlie Terrane, Western Australia: Part 1. Deposit and Endowment Density Models, Ore Geology Reviews, 37(3-4), 2010, pp. $141-157$.

11. Marsden, J. E., and Tromba, A. J., Vector Calculus, W. H. Freeman and Company, New York, 1988.

12. McInnes, B. I. A., Dunn, C. E., Cameron, E. M., and Kameko, L., Biogeochemical Exploration for Gold in Tropical Rain Forest Regions of Papua New Guinea, Journal of Geochemical Exploration, 57(1-3), 1996, pp. $227-243$.

13. Miller, W. R., Ficklin, W. H., and McHugh J. B., Geochemical Exploration for Copper-Nickel Deposits in the Cool-Humid Climate of Northeastern Minnesota, Journal of Geochemical Exploration, 42(2-3), 1992, pp. 327 - 344.

14. Moradi, A. B., Swoboda, S., Robinson, B., Prohaska, T., Kaestner, A., Oswald, S. E., Wenzel, W. W., and Schulin, R., Mapping of Nickel in Root Cross-Sections of the Hyperaccumulator Plant Berkheya Coddii Using Laser Ablation ICP-MS, Environmental and Experimental Botany, 69(1), 2010, pp. 24-31.

15. Porwal, A., González-Álvarez, I., Markwitz, V., McCuaig, T. C., and Mamuse, A., Weights of Evidence and Logistic Regression Modeling of Magmatic Nickel Sulfide Prospectivity in the Yilgarn Craton, Western Australia, to appear Ore Geology Reviews, 2011.

16. Sibbick, S. J., and Fletcher, W. K., Distribution and Behavior of Gold in Soils and Tills at the Nickel Plate Mine, Southern British Columbia, Canada, Journal of Geochemical Exploration, 47(1-3), 1993, pp. $183-200$.

17. Taylor, A. E., and Mann, W. R., Advanced Calculus. John Wiley and Sons, Inc. New York, 1983.

18. Worthington, J. E., Jones, E. M., and Kiff, I. T., Techniques of Geochemical Exploration in the Southeast Piedmont of the United States, Journal of Geochemical Exploration, 6(1-2), 1976, pp. $279-295$. 